\title{
Turbulent surface fluxes and air-ice coupling in the Baltic Air-Sea-Ice Study (BASIS)
}

\author{
Jouko Launiainen, Bin Cheng, Juha Uotila, Timo Vihma \\ Finnish Institute of Marine Research, P.O. Box 33, FIN-00931 Helsinki, Finland
}

\begin{abstract}
Turbulent surface fluxes were studied using observations taken over sea ice in the Baltic Sea in March 1998. The fluxes of momentum and sensible heat were measured by a sonic anemometer and compared with fluxes derived from wind velocity and air-temperature profiles. The neutral $10 \mathrm{~m}$ drag coefficient showed no apparent dependence on wind speed (in the range $2-20 \mathrm{~m} \mathrm{~s}^{-1}$ ), resulting in a mean value of $1.0 \times 10^{-3}$ for smooth snowcovered ice and $1.5 \times 10^{-3}$ for deformed ice. The overall mean value was $1.28 \times 10^{-3}$. The roughness length for temperature revealed a greater apparent dependence on wind speed and was slightly larger than the aerodynamic roughness for low wind speeds, and vice versa for moderate and high winds. We give an empirical expression that predicts how the scalar roughness depends on the aerodynamic roughness (drag coefficient) and wind speed. Agreement of the gradient-method results with the eddy-flux results supports the validity of the MoninObukhov similarity theory. Fluxes modelled by a coupled air-ice-sea model compared well with the eddy-flux and gradient methods. Surface temperature estimates by the three methods also agreed well. Tests and sensitivity analysis emphasize the need for especially accurate sensor calibration and strict information about the sensor heights for the gradient method.
\end{abstract}

\section{INTRODUCTION}

Accurate estimation of local turbulent surface fluxes is a fundamental problem in air-ice interaction studies (Hicks and Martin, 1972; Banke and others, 1980; Andreas, 1987; King and Anderson, 1994; Smeets and others, 1999) and modelling efforts (Launiainen and Cheng, 1998). Knowledge of the local fluxes is also a prerequisite for estimating and modelling regional fluxes over a heterogeneous surface, formed by a mosaic of ice of various ice thickness, and cracks and leads (Claussen, 1991; Vihma, 1995; Essery, 1997).

Determination of the turbulent fluxes, air-ice-ocean coupling, and modelling are important goals in the Baltic Air-Sea-Ice Study (BASIS) project. In air-ice coupling, the primary quantities studied include fluxes of momentum, heat, water vapour (latent heat), radiative fluxes and air-ice interfacial (surface) temperature. In this paper, we describe Finnish Institute of Marine Research process studies of local air-ice coupling based on measurements carried out at the RV Aranda ice station.

BASIS was a sub-project of the Baltic Sea program BALTEX of the World Climate Research Programme/Global Energy and Water Cycle Experiment. The objective of BASIS was to create and analyze an experimental dataset for optimization and verification of coupled atmosphere-ice-ocean models. The project was conducted by various Finnish, Swedish and German institutes during 1997-2000. The main field campaign was carried out in February-March, 1998 in the northern Baltic Sea. The location of the intensive measuring network was in the boundary zone between the ice-covered and open sea. The experiment and the data are described in the BALTEX-BASIS data report (Launiainen, 1999).

\section{OBSERVATIONS AND METHODS}

\section{Measurements}

Measurements focused on air-ice coupling included momentum and sensible-heat eddy-flux measurements (sonic anemometer Metek USA-1 with a path length of $180 \mathrm{~mm}$, at a height of $2.25 \mathrm{~m}$ ), together with wind and air-temperature measurements on a $10 \mathrm{~m}$ high profile mast on the sea ice. The wind speed was measured at five levels (at nominal heights of 10.13, $4.73,2.43,1.23$ and $0.53 \mathrm{~m}$ ) using cup anemometers (Aanderaa Instruments Co.). Temperature was measured at three levels $(10.08,2.38$ and $0.48 \mathrm{~m})$ using film-type platinum resistors (Aanderaa Instruments Co.). Profile gradients from the mast allow us to calculate the fluxes of momentum and sensible heat for comparison with eddy-flux results. A geometric redress procedure was used to correct the sonic anemometer data for a potential tilt error of the axis, especially a deviation of the $z$ axis from the vertical. Sensor calibration of the mast was done in a wind tunnel and a temperature test tank before and after the fieldwork, with specific attention paid to the mutual comparison of the sensors. In addition to the sonic and mast measurements, radiation fluxes were measured, and in-ice and insnow temperature time series observed. Finally, water-ice fluxes of heat, momentum and salt were measured with eddy-flux equipment below the ice. General meteorological 
wind, temperature and radiation conditions during BASIS are described by Cheng and others (2001).

\section{Methods}

Fluxes, gradient and bulk aerodynamic calculations

In a surface boundary layer, the turbulent fluxes (a) of momentum $(\tau)$ and sensible heat $(H)$ can be expressed in the gradient (b) and bulk forms (c):

$$
\begin{array}{cl}
\tau=-\overline{\rho u^{\prime} w^{\prime}} \simeq \rho K_{\mathrm{M}} \frac{\partial V}{\partial z}= & \rho u_{*}^{2}=\rho C_{\mathrm{D}} V_{z}^{2} \\
H=\overline{\rho c_{\mathrm{p}} \Theta^{\prime} w^{\prime}} \simeq \rho c_{\mathrm{p}} K_{\mathrm{H}} \frac{\partial \Theta}{\partial z}= & \rho c_{\mathrm{p}} C_{\mathrm{H}}\left(\Theta_{\mathrm{s}}-\Theta_{z}\right) V_{z},
\end{array}
$$

(a)

(b)

where $V_{z}$ is wind speed at a height $z, u_{*}$ is friction velocity, $\Theta$ is potential temperature, $\rho$ is air density and $c_{\mathrm{p}}$ is specific heat capacity of air. $\Theta_{\mathrm{s}}-\Theta_{z}$ is the difference in potential temperature between the surface and the air. $K_{\mathrm{M}}$ and $K_{\mathrm{H}}$ are the gradient-method eddy diffusivities for momentum and heat.

For most marine and over-ice studies, the fluxes have to be estimated using the bulk formulae (c). From the MoninObukhov (M-O) similarity theory connecting the fluxprofile relationships and the bulk transfer coefficients (see Garratt, 1992; Launiainen, 1995), the bulk transfer coefficients for momentum $\left(C_{\mathrm{D}}\right)$ and heat $\left(C_{\mathrm{H}}\right)$ are defined as

$$
\begin{aligned}
& C_{\mathrm{D}}=C\left[z, z_{0}, \Psi_{\mathrm{M}}(z / L)\right], \\
& C_{\mathrm{H}}=C\left[z, z_{0}, z_{\mathrm{T}}, \Psi_{\mathrm{M}}(z / L), \Psi_{\mathrm{H}}(z / L)\right],
\end{aligned}
$$

where $z_{0}$ and $z_{\mathrm{T}}$ are the roughness lengths for velocity and temperature, respectively, and $\Psi_{\mathrm{M}}$ and $\Psi_{\mathrm{H}}$ are universal functions which give the effect of atmospheric stratification in terms of the Obukhov length $L$. The effects of stability and the universal functions vanish in neutral conditions. The above formulation indicates that, for estimation of fluxes by bulk formulae, the local aerodynamic roughness lengths $\left(z_{0}, z_{\mathrm{T}}\right)$ or the local, neutral bulk transfer coefficients $\left(C_{\mathrm{D}}\right.$, $\left.C_{\mathrm{H}}\right)$ must be known. In addition, because the case-specific parameter $L$ (in the argument of the universal functions) includes the fluxes to be defined, the bulk calculation leads to an iterative solution, except in a rough first-order estimation not taking the stability explicitly into account.

Using eddy covariance equipment, the fluxes can be measured directly according to the (a) forms of Equations (1) and (2). This yields data for derivation of the bulk form coefficients as well. Based on the M-O similarity theory, the fluxes can also be defined from profile gradient measurements, because the profile gradient form (b) transfer coefficients can be written as

$$
K_{\mathrm{M}}=\frac{k u_{*} z}{\Phi_{\mathrm{M}}(z / L)}, \quad K_{\mathrm{H}}=\frac{k u_{*} z}{\Phi_{\mathrm{H}}(z / L)}
$$

where the functions $\Phi_{\mathrm{M}}$ and $\Phi_{\mathrm{H}}$ are the gradient-form universal functions for velocity and temperature, and $k$ is the von Kármán constant. By making accurate gradient measurements, we may solve for the fluxes from Equations (1b), (2b) and (4). Accordingly, a gradient of wind speed with respect to height gives $u_{*}$ and $\tau$ from Equations (4) and (lb). Then the temperature gradient yields the heat flux $H$. However, we should again note that, because the argument $(z / L)$ in the universal functions $\Phi_{\mathrm{M}}$ and $\Phi_{\mathrm{H}}$ includes the fluxes to be solved $\left(u_{*}, H\right)$, the final solution is iterative. For our study, a modified algorithm developed by Launiainen and Vihma (1990) was applied. Regarding the universal functions, for the unstable regions the Businger and others (1971)-Dyer (1974)type forms with Högström's (1988) coefficients were adopted, while for the stable region those of Holtslag and de Bruin (1988) were used. Exact formulae are given in Launiainen (1995, p. 177-178).

As for the water-vapour flux or latent heat, M-O similaritytheory-based forms analogous to those for sensible heat can also be derived. In our study, however, no eddy-flux equipment was used. Instead, we estimated these fluxes using a singlelevel moisture measurement and an inverse method. We first estimated the surface temperature using Equation (6) below, and assumed that the specific (saturation) humidity was determined by the surface temperature. We then used the bulk form to calculate the fluxes. The results are not reported here. We believe that the gradient method for the water-vapour and latent-heat flux is inaccurate in cold conditions, due to the very small humidity gradients.

\section{Coupled model}

As a third method to determine the turbulent surface fluxes, a coupled one-dimensional, multi-layer thermodynamic model (Launiainen and Cheng, 1998; Cheng and others, 2001) was used. In the model, air and snow/ice are coupled by the heat fluxes, and the interface temperature calculated at each timestep. In addition to the ice thermodynamics, the model produces air-ice fluxes, the stability parameter and profiles of wind speed, temperature and moisture. As meteorological input, the model uses a level wind speed, temperature and moisture. These may be arbitrary and mutually different. The model has been tested and yields accurate heat fluxes, momentum flux, surface energy balance, surface temperature and in-ice temperatures. For bulk calculation of the fluxes, the modelled surface temperature is used, so the method is practically independent of the eddy-flux and gradient methods described above.

\section{RESULTS AND DISGUSSION}

\section{Drag coefficient and aerodynamic roughness length}

The neutral drag coefficient $C_{\mathrm{DN}}$ derived from the momentum flux measurements, Equation (la), and corrected for stability $C_{\text {DN }}=k^{2} /\left(\ln z / z_{0}\right)^{2}$, is shown as a function of wind speed in Figure 1. The results show no apparent wind-speed dependence; the mean $C_{\mathrm{DN}}(10)=1.28 \times 10^{-3}$ corresponds to a mean aerodynamic roughness length $z_{0}=1.2 \times 10^{-4} \mathrm{~m}$. All 13 points corresponding to the highest wind velocities and higher drag coefficients are from the same snowstorm episode. During this storm, blowing snow and sastrugi were observed on the surface, which might explain the higher drag coefficients. The results are regarded as generally reliable because the drag coefficients based on the abovedescribed profile gradient method from Equations (lb), (4) and (1c) resulted in drag coefficients (not quantitatively shown here) very like those in Figure 1. The experimental site was located in an archipelago in a coastal area surrounded by an asymmetric island and coastline geometry and orography, with asymmetric roughness along the wind direction. Investigation of the neutral drag coefficient indicated an apparent dependence on the wind direction, i.e. a dependence on the geometric roughness of the sea ice and that of the land and archipelago in the coastal direction. This can be seen from Figure 2, which gives the neutral drag coefficient vs the wind direction, as projected on a map of the observation 


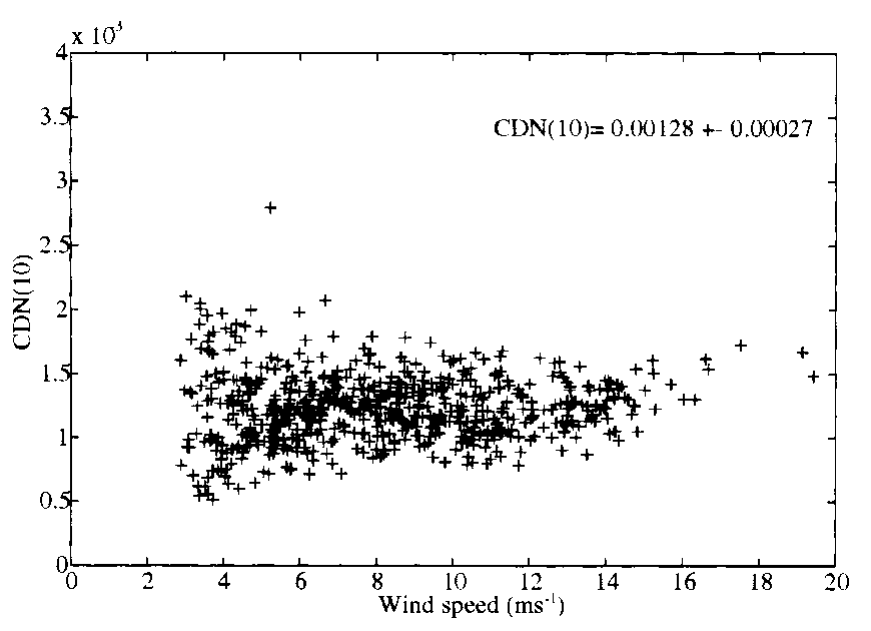

Fig. 1. Eddy-flux-derived drag coefficient $C_{\mathrm{DN}}(10)$ as a function of wind speed at the RVAranda ice station during BASIS-98, 17 February-6 March 1998 (0.5 h means).

area. The drag coefficient shows interesting behaviour. From the direction of the archipelago (north and northeast) with a short fetch, the drag coefficient is comparatively high. From the south, west and northwest, the drag coefficients pretty well correspond with the main characteristics of the sea ice along the upwind fetch. Although the results seem reasonable, the upwind fetch in the direction of the deformed ice was unfortunately not homogeneous, and the strict geometric/aerodynamic sea-ice roughness ratio quantification still seems to remain semi-quantitative. An analysis with respect to helicopter laser roughness profiling data is in progress. Based on visual observations, RADARSAT images and photographs from a helicopter, we assume the drag coeffi-

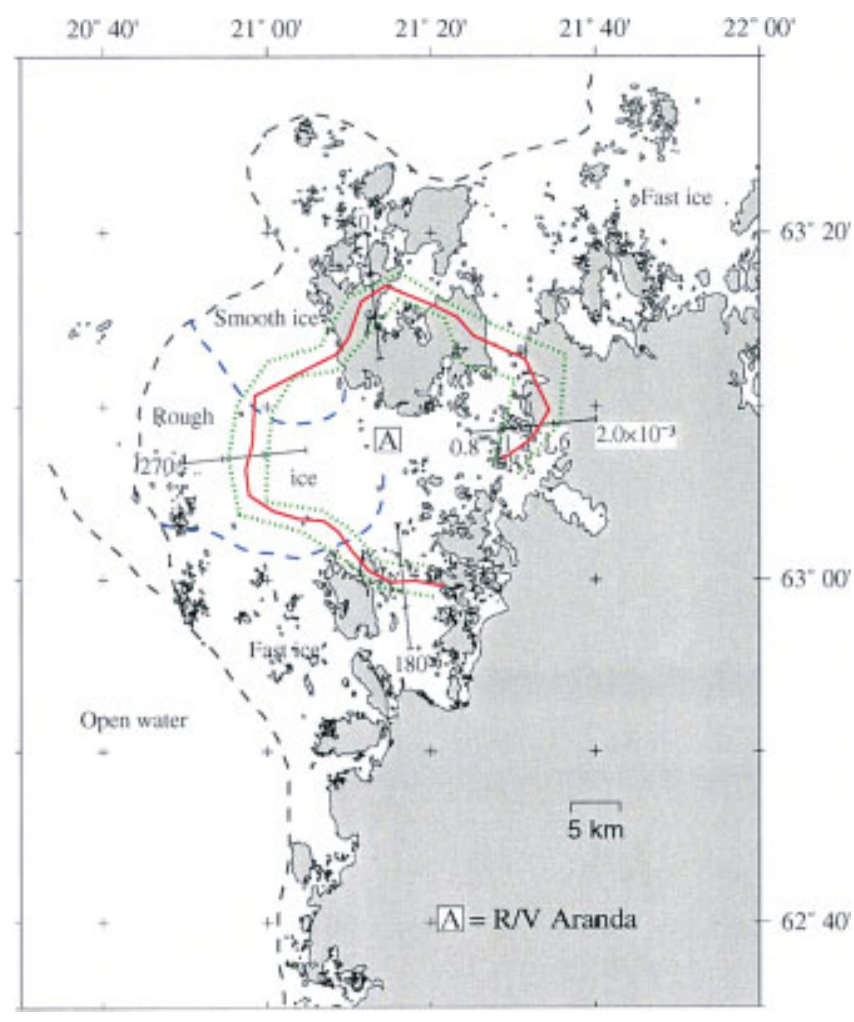

Fig. 2. Drag coefficient (red line) and its deviation vs the wind direction (green dotted line) observed at the $R V$ Aranda ice station ( $A)$, as projected on a map of the observation area in the archipelago in the northern Baltic Sea. cient $C_{\mathrm{DN}}(10)$ to be $1.0 \times 10^{-3}\left(z_{0} \cong 2.7 \times 10^{-5} \mathrm{~m}\right)$ for the smooth snow-covered ice, and $1.5 \times 10^{-3}\left(z_{0} \cong 2.9 \times 10^{-4} \mathrm{~m}\right)$ for the rougher ice in the west, which was refrozen from broken ice fields. Even so, no apparent wind-speed dependence of aerodynamic roughness or drag coefficient was found for any of the surface types.

As for the characterization of "rougher" ice, we are speaking here about thin (0.3-0.4 m) deformed Baltic Sea coastal ice of $100 \%$ concentration which included no ridges or roughness elements higher than $0.3-0.6 \mathrm{~m}$. Therefore, when compared to the northern polar sea-ice roughness classification of Quest and Davidson (1991), our field site would correspond to very smooth or smooth first- or multi-year sea ice with no pressure ridges. Actually, the numerical drag-coefficient results and (more or less subjective) ice-roughness characterization in the literature vary quite a lot, as is evident, for example, from Hofmann (1998, table 4.1); sea-ice roughness information is given, almost without exception, in qualitative or semi-quantitative terms. The above definition and numerical uncertainty may be reflected in part as a large variability in the drag coefficients used by models in atmosphere-ice momentum-flux calculations (Harder and Fischer, 1999). We believe that for a "universal" resistance quantification and characterization of sea ice, we still need additional highquality aerodynamic roughness data, as well as quantification of the height and distribution of the geometric roughness elements (cf. the nice effort by Banke and others, 1980). For very rough ice conditions and in conditions of ice concentration where ice concentration is $<1$, this would allow a reasonable partition of the total drag resistance into form drag and skin drag (Mai and others, 1996; Garbrecht and others, 1999).

\section{Heat-transfer coeffient and temperature roughness length}

Estimation of the bulk heat-exchange coefficient $\left(C_{\mathrm{H}}\right)$ or the temperature roughness length $\left(z_{\mathrm{T}}\right)$ is more problematic. For determination of the bulk heat-transfer coefficient from Equation (2c), accurate surface temperatures need to be known. Experience gained from BASIS suggests that derivation of the surface temperature, even from radiation measurements, is not always trivial and is insufficiently accurate for the purpose. We studied the temperature roughness length in conditions for which we believe the estimation of the surface temperature was quite accurate, i.e. when the temperature remained at the freezing point. We first calculated the air-ice interface temperature using the coupled thermodynamic model. In cases for which the model estimates an apparent positive surface heat balance and melting, we assumed a surface temperature of $0^{\circ} \mathrm{C}$. Under variable and mild weather during the field campaign, we had several periods of such conditions (cf. Fig. 6, shown later). For those cases we could then calculate the bulk transfer coefficients and the roughness length for temperature from Equations (2) and (3).

The results indicated that the temperature roughness and aerodynamic roughness were of the same order of magnitude, and that the scalar roughness was slightly larger than the aerodynamic roughness for low wind velocities, although $z_{\mathrm{T}}<z_{0}$ for winds higher than 4-5 $\mathrm{m} \mathrm{s}^{-1}$. An apparent dependence of $z_{\mathrm{T}}$ on wind speed was found showing that $z_{\mathrm{T}}$ decreased with wind. The results are shown in Figure 3 in terms of the aerodymamic to scalar roughness length ratio of $\ln \left(z_{0} / z_{\mathrm{T}}\right)=k B^{-1}$ plotted with respect to a roughness 


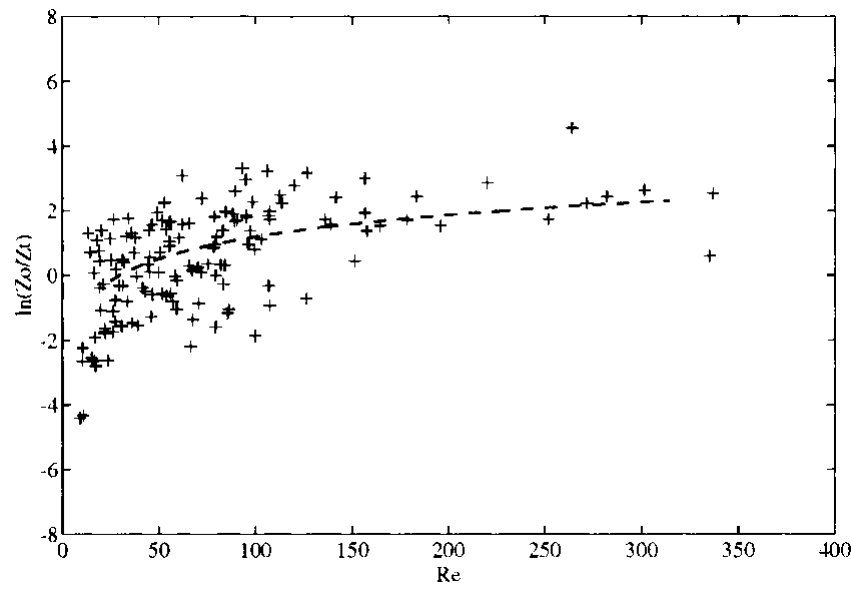

Fig. 3. Ratio of the aerodynamic roughness to the temperature roughness $\ln \left(z_{0} / z_{\mathrm{T}}\right)$ as a function of the roughness Reynolds number $\left(\operatorname{Re}=z_{0} V \nu^{-1}\right)$. A fit $z_{0} / z_{\mathrm{T}}=0.035 \operatorname{Re}^{0.98}$ is given as dashed line $(20<\operatorname{Re}<300)$.

Reynolds number, in order to make the results less casespecific. The Reynolds number we use is defined as $\mathrm{Re}=$ $\left(z_{0} V\right) \nu^{-1}$, where $\nu$ is the kinematic viscosity. We prefer this Reynolds number to the commonly used $\operatorname{Re}=\left(z_{0} u_{*}\right) \nu^{-1}$ (e.g. Owen and Thomson, 1963; Andreas, 1987) because we do not have an accurate method to simultaneously obtain $z_{0}$ and $u_{*}$ independently of each other. This is needed to avoid a spurious correlation, since $z_{0}$ and $u_{*}$ are essentially governed by the same profile equation of wind speed (cf. Launiainen, 1983, p. 482). This kind of spurious correlation tends to hide and smooth out even large experimental errors and scatter in the data. In terms of Re, a fit with our $\ln \left(z_{0} / z_{\mathrm{T}}\right)$ data is given in Figure 3.

As parameterized, our results of $\ln \left(z_{0} / z_{\mathrm{T}}\right)$ can be written in a linear form as

$$
\begin{aligned}
\ln \left(z_{0} / z_{\mathrm{T}}\right) & =s+a V \quad \text { or } \\
C_{\mathrm{HN}} & =k C_{\mathrm{DN}}^{1 / 2}\left(\ln z / z_{\mathrm{T}}\right)^{-1} \\
& \cong C_{\mathrm{DN}}\left[1+C_{\mathrm{DN}}^{1 / 2} k^{-1}(s+a V)\right]^{-1},
\end{aligned}
$$

where $C_{\mathrm{DN}}=k^{2}\left[\ln \left(z / z_{0}\right)\right]^{-2}$ and $s=-0.80$. $a=0.15$ for wind speed at a height of $2 \mathrm{~m}$, while for a wind referred to $10 \mathrm{~m}, a=$ 0.13 . For a site with $C_{\mathrm{DN}}$ or $z_{0}$ known or estimated, Equation (5) should give a reasonable estimate of $C_{\mathrm{H}}$ and $z_{\mathrm{T}}$.

The region of our $z_{0}$ observations in the analysis was limited to $3 \times 10^{-5}$ to $9 \times 10^{-4} \mathrm{~m}$, i.e. $C_{\mathrm{DN}}(10)=1.0 \times 10^{-3}$ to $1.9 \times 10^{-3}$ and wind speeds of $3-15 \mathrm{~m} \mathrm{~s}^{-1}$. The analysis (Fig. 3) suggests that, for higher aerodynamic roughness and wind speeds, an asymptotic value $\ln \left(z_{0} / z_{\mathrm{T}}\right) \cong 2$ is attained. This value is in good agreement with the findings of Garratt (1978, 1992) for rough surfaces with $z_{0} / z_{\mathrm{T}}=7.3$. Accordingly, our results might serve as proper first estimates for even higher wind speeds and roughness lengths. Generally, the dependence of the roughness ratio found above is in agreement with wind-tunnel studies, theoretical arguments and parameterizations for conditions over natural surfaces (Owen and Thomson, 1963; Andreas, 1987; Garratt, 1992) and with field studies (Hicks and Martin, 1972; Joffre, 1982). Strictly, however, our results cannot be quantitatively compared with those of Andreas (1987) because of our different definition of Re. Still, if we estimate $\ln \left(z_{0} / z_{\mathrm{T}}\right)$ according to Andreas (1987), using our mean $z_{0}$ and $u_{*}=f\left(z_{0}, V\right.$, stability $)$, the results are in rather good agreement with our data. King
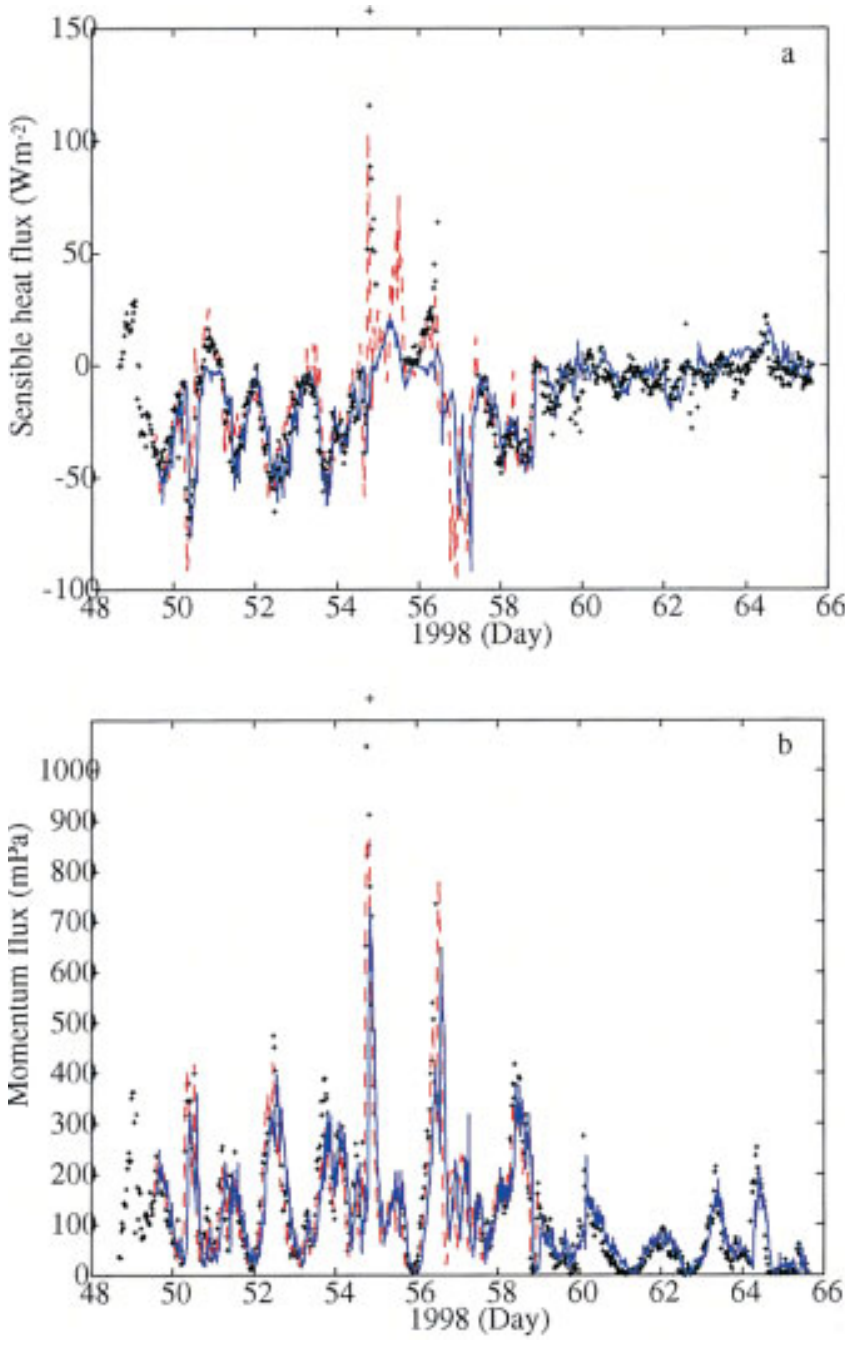

Fig. 4. Time series of the sensible-heat flux (a) and momentum flux (b). Crosses give the results of the eddy-flux observations. Dashed red line gives the gradient-method result (LDM), and the blue line is the estimation by the coupled ice model $(0.5 \mathrm{~h}$ means).

and Anderson (1994) obtained the unusual result of $z_{\mathrm{T}} \gg z_{0}$ over an Antarctic ice shelf. It is not known whether the reason for this anomalous roughness ratio was an overestimation of the temperature of the snow surface, the surface being cooled down by thermal radiative fluxes. The experience gained from determining $z_{\mathrm{T}}$ with these data and from estimating the surface temperature with our coupled thermodynamic model supports this conclusion.

\section{Fluxes and surface temperature}

As described above, in addition to the sonic anemometer eddy fluxes, the profile gradient data provided us with an independent method to determine the turbulent fluxes and transfer coefficients. The results of the gradient-method calculations are compared with the eddy-flux results in Figure 4a and b; fluxes calculated with the thermodynamic ice model are also shown for comparison. The gradient method (also called the level-difference method (LDM)) results shown are based on measurements from the (nominal) levels of 2.4 and $0.5 \mathrm{~m}$. The results indicate the eddy-flux and gradient methods agree well. The sensible-heat flux comparison is given in Figure 4a only up toJulian day 59 in 1998. The LDM results were not presented in the comparison after this date because the LDM was inaccurate due to very low wind speeds, small 


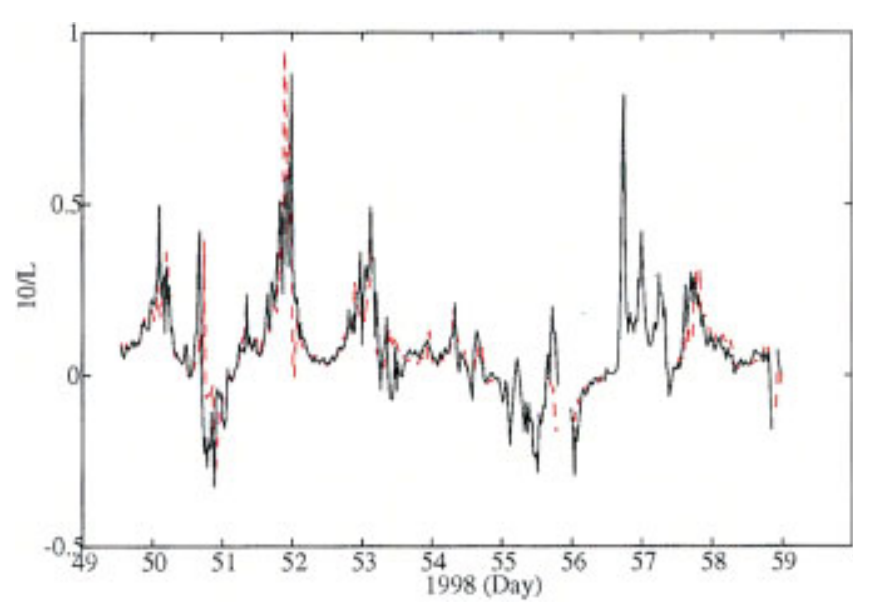

Fig. 5. Time series of the stability parameter $10 / L$ as calculated from the eddy-flux results (dashed red line) and profile gradient method (solid line).

turbulent fluxes and large interfering daily shortwave radiation fluxes.

As may be expected from the agreement in the fluxes, the transfer coefficients $\left(C_{\mathrm{D}}, C_{\mathrm{H}}\right)$ based on the sonic anemometer and LDM indicate good agreement in both the neutral and diabatic conditions. Strictly, however, a detailed analysis of the observed diabatic eddy-flux-based transfer coefficients with the observed fluxes and the M-O similarity-theorybased flux-profile relationships suggests that the current universal functions for the stable region suppress the turbulence and transfer coefficients too much. For stability up to $10 / L=$ 0.5, the well-known universal functions of Webb (1970) and Holtslag and de Bruin (1988) yield 10-12\% lower bulk transfer coefficients than those defined from our data. For $10 / L=$ 1, the above difference was 15-17\% . Actually, the non-linear Holtslag and de Bruin (1988) form, defined particularly for the strongly stable region, gives essentially the same results for less stable conditions of $z / L$ (up to 0.5 or 1 ) as the usual linear form by Webb (1970), the upper limit of this agreement depending on the aerodynamic roughness (cf. Launiainen, 1995). The search for an improved universal function form is still in progress.

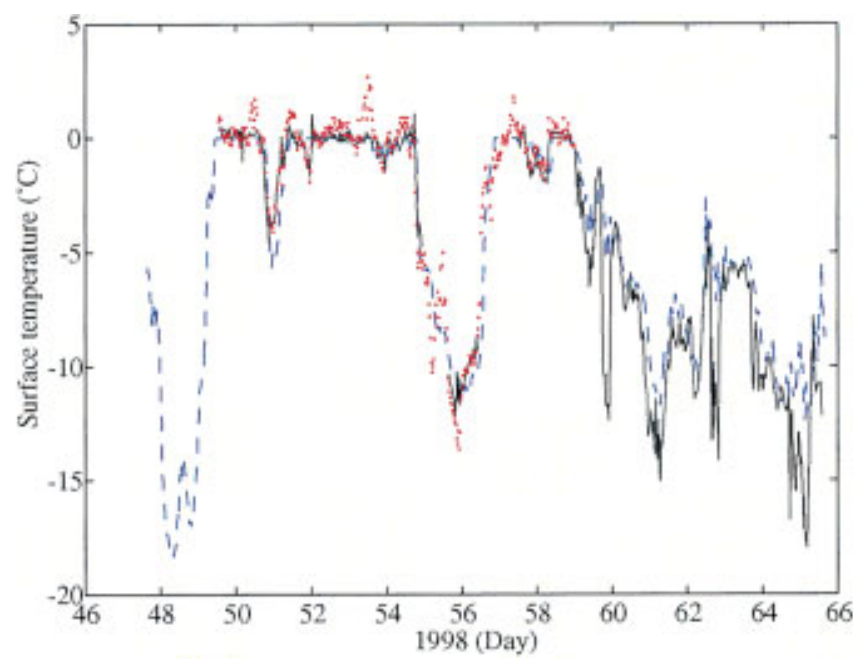

Fig. 6. Surface temperature during BASIS as derived by the coupled model (dashed blue line) and by Equation (6), using the eddy-flux data (solid line) and profile gradient data (dotted red line).
The flux estimates using the coupled thermodynamic ice model generally agree with those of the two other methods. However, during the latter part of the study period, from day 59 onwards, the magnitude of the sensible-heat flux tends to be too small for any quantitative comparison (Fig. 4a). During days 54-56, the ice model seems to smooth out the high, short-period flux variations. These days were connected with cold snowstorms. On the other hand, the momentum flux is well estimated, even during the large peaks in Figure 4b. This prompts us to investigate whether the heat-flux smoothing is due to a thermal "inertia" in the ice model. This will be studied using a shorter model time-step than in previous simulations.

The time series of the stability parameter $z / L$ is given in Figure 5. As can be seen, the stability characteristics derived from the direct eddy-flux measurements and LDM are almost identical.

Finally, we may calculate and compare the various estimates of the surface temperature. When integrated, the fluxprofile gradient relation (2) gives

$$
T_{\mathrm{s}}=\Theta_{z}+\frac{H\left[\ln z / z_{0}-\Psi_{\mathrm{M}}(z / L)\right]\left[\ln z / z_{\mathrm{T}}-\Psi_{\mathrm{H}}(z / L)\right]}{\rho c_{\mathrm{p}} k^{2} V_{z}} .
$$

Estimates according to Equation (6), based on both the sonicanemometer and LDM data, were calculated. The results are shown in Figure 6, together with the surface temperature predicted by the ice model. (Even for the LDM-based estimate, the $z_{\mathrm{T}}$ used was that derived above from the eddy-flux data, but this has a minor effect on the results.) As can be seen, the three alternatives generally agree well and seem to be effective tools for surface temperature estimation. This was confirmed by temperature estimates based on thermal radiation measurements during the first half of the measurement period (for clarity, not shown in Figure 6). However, in conditions of small fluxes but large variations in meteorological forcing (as from day 59 onwards), the ice model may not follow all the variations, whereas the other methods (especially the sonic-anemometer-based surface temperature) resolved them well. This conclusion was supported by the variations in the temperature estimate based on thermal radiation measurements.

\section{CONGLUSIONS}

To summarize, we believe that the turbulent transfer coefficients and fluxes for the BASIS ice station are determined accurately. The drag coefficient (aerodynamic roughness) did not reveal a wind-speed dependence. The agreement of the gradient-method results with the eddy-flux results supports the validity of the M-O similarity theory, in conditions satisfying the preconditions for the theory. Fluxes modelled by the coupled air-ice model also compared reasonably well with the eddy-flux and gradient methods.

Analysis of the roughness lengths indicated that the temperature roughness was comparable to, or slightly larger than, the aerodynamic roughness for low wind speeds, while $z_{0}>z_{\mathrm{T}}$ for moderate and strong winds. Accordingly, the temperature roughness length and bulk heat-transfer coefficients can be reasonably approximated by Equation (5) for winds up to $20 \mathrm{~m} \mathrm{~s}^{-1}$.

Surface temperature estimation by all three methods compared well, and these may (except for some limitations 
relating to the ice model) serve as a tool for temperature estimation. The flux verification and temperature comparison justify the overall relevancy of the ice-model construction and indicate the model's potential for process studies.

Finally, we cannot overemphasize the need for accurate and strict calibration of sensors, especially for the gradient method. In addition to the sensor calibration (temperature, wind speed), we note that an inaccuracy in the measuring heights of even as little as, say, $5 \mathrm{~cm}$ when defining gradients in the lowest few metres causes significant error $(\sim 10 \%)$ in fluxes and bulk transfer coefficients determined by the LDM method.

\section{AGKNOWLEDGEMENTS}

We are grateful to the participants in the BASIS-98 field campaign. The study is a part of the project BALTEX-BASIS supported by the European Commission under the contract MAST3-CT97-0117. E. Andreas (Cold Regions Research and Engineering Laboratory, Hanover, NH, U.S.A.) and P. Guest (Naval Postgraduate School, Monterey, CA, U.S.A.) are acknowledged for their critical review of the paper.

\section{REFERENGES}

Anderson, R. J. 1987. Wind stress measurements over rough ice during the 1984 marginal ice zone experiment. F. Geophys. Res., 92(C7), 6933-6941.

Andreas, E. L. 1987. A theory for the scalar roughness and the scalar transfer coefficients over snow and sea ice. Boundary-Layer Meteorol., 38(1-2), 159-184.

Banke, E. G., S. D. Smith and R. J. Anderson. 1980. Drag coefficients at AIDJEX from sonic anemometer measurements. International Association of Hydrological Sciences Publication 124 (Symposium at Seattle 1977 - Sea Ice Processes and Models), 430-442.

Businger, J. A., J. C. Wyngaard, Y. Izumi and E. F. Bradley. 1971. Flux-profile relationships in the atmospheric surface layer. f. Atmos. Sci., 28, 181-189.

Cheng, B., J. Launiainen, T. Vihma and J. Uotila. 2001. Modelling sea-ice thermodynamics in BALTEX-BASIS. Ann. Glaciol., 33 (see paper in this volume).

Claussen, M. 1991. Estimation of areally-averaged surface fluxes. BoundaryLayer Meteorol., 54(4), 387-410.

Dyer, A.J. 1974. A review of flux-profile relationships. Boundary-Layer Meteorol., 7, 363-372.

Essery, R. L. H. 1997. Modelling fluxes of momentum, sensible heat and latent heat over heterogenous snow cover. Q. F. R. Meteorol. Soc.,
123 (A543), 1867-1883.

Garbrecht, T., C. Lubkes, E. Augstein and C. Wamser. 1999. Influence of a sea ice ridge on low-level air-flow. F. Geophys. Res., 104 (D20), 24,499-24,507.

Garratt, J. R. 1978. Flux profile relations above tall vegetation. Q. F. R. Meteorol. Soc., Ser. A, 104(543), 199-211.

Garratt, J. R. 1992. The atmospheric boundary layer. Cambridge, Cambridge University Press.

Harder, M. and H. Fischer. 1999. Sea ice dynamics in the Weddell Sea simulated with an optimized model. 7. Geophys. Res., 104(C5), 11,151-11,162.

Hicks, B. B. and H. C. Martin. 1972. Atmospheric turbulent fluxes over snow. Boundary-Layer Meteorol., 2, 255-265.

Hofmann, M. 1998. Untersuchungen zur Atmosphärischen Turbulenz über Aarktischen Meereis mit der Hubschrauberschleppsonde HELIPOD. Berichte des Instituts für Meteorologie und Klimatologie der Universität Hannover 59.

Högström, U. 1988. Non-dimensional wind and temperature profiles in the atmospheric surface layer: a re-evaluation. Boundary-Layer Meteorol., 42, $55-78$.

Holtslag, A. A. M. and H. A. R. de Bruin. 1988. Applied modeling of the nighttime surface energy balance over land. 7. Appl. Meteorol., 37, 689-704.

Joffre, S. M. 1982. Momentum and heat transfers in the surface layer over a frozen sea. Boundary-Layer Meteorol., 24(2), 211-229.

King, J. C. and P. S. Anderson. 1994. Heat and water vapour fluxes and scalar roughness lengths over an Antarctic ice shelf. Boundary-Layer Meteorol., 69(1-2), 101-121.

Launiainen, J. 1983. Parameterization of the water vapour flux over a water surface by the bulk aerodynamic method. Annales Geophysicae, 1 (6), 481-492.

Launiainen, J. 1995. Derivation of the relationship between the Obukhov stability parameter and the bulk Richardson number for flux-profile relationships. Boundary-Layer Meteorol., 76, 165-179.

Launiainen, J., ed. 1999. BALTEX-BASIS data report 1998. Geesthacht, International BALTEX Secretariat. (Publication 14.)

Launiainen, J. and B. Cheng. 1998. Modelling of ice thermodynamics in natural water bodies. Cold Reg. Sci. Technol., 27(3), 153-178.

Launiainen, J. and T. Vihma. 1990. Derivation of turbulent surface fluxes - an iterative flux-profile method allowing arbitrary observing heights. Environmental Software, 5, 113-124.

Mai, S., C. Wamser and Ch. Kottmeier. 1996. Geometric and aerodynamic roughness of sea ice. Boundary-Layer Meteorol., 77(3-4), 233-248.

Owen, P. R. and W. R. Thomson. 1963. Heat transfer across rough surfaces. f. Fluid Mech., 15, 321-334.

Quest, P. S. and K. L. Davidson. 1991. The aerodynamic roughness of different type of sea ice. 7. Geophys. Res., 96(C3), 4709-4721.

Smeets, C. J. P. P., P. G. Duynkerke and H. F. Vugts. 1999. Observed wind profiles and turbulence fluxes over an ice surface with changing surface roughness. Boundary-Layer Meteorol., 92, 101-123.

Vihma, T. 1995. Sub-grid parameterization of surface heat and momentum fluxes over polar oceans. 7. Geophys. Res., 100 (C11), 22,625-22,646.

Webb, E. K. 1970. Profile relationships: the log-linear range, and extensions to strong stability. Q. F. R. Meteorol. Soc., 96, 67-90. 